\title{
ANALISIS TINDAK TUTUR PIDATO PRESIDEN JOKOWI PADA APEC 2014 DI CINA
}

\author{
Edward, Sorta Hutahaean \\ Fakultas Ilmu Budaya, Universitas Lancang Kuning, \\ Pekanbaru \\ sortahutahaean02@gmail.com
}

\begin{abstract}
This research is entitled "the analysis of illocutionary speech act of president Jokowi in APEC, China 2014”. The research was aimed at exploring and identifying speech acts uttered by president Jokowi in his presidential speech in China, 2014. Levinson (1983) proposed that the interest of pragmatic study was based on its empirical and descriptive way. Hence, this research was aimed at exploring and identifying illocutionary forms uttered by president Jokowi in his presidential speech in China, 2014. The research shows that factors of situation, place, topic, speaker and context play significantly as important roles. The form of structure of the speech was more on representative functioning to inform and invite.
\end{abstract}

Keywords: form, speech act,

\section{function PENDAHULUAN}

\begin{tabular}{lrrr} 
Bidang & \multicolumn{2}{c}{ pragmatik } & dalam \\
linguistik dewasa ini & mulai \\
mendapat perhatian para & peneliti \\
dan pakar bahasa di Indonesia.
\end{tabular}

Bidang ini cenderung mengkaji fungsi ujaran atau fungsi bahasa daripada bentuk atau strukturnya dengan kata lain, pragmatik lebih cenderung ke fungsionalisme daripada ke formalisme. Hal itu sesuai dengan pengertian pragmatik yang dikemukakan oleh Levinson (1987: 5 dan 7), pragmatik adalah kajian mengenai penggunaan bahasa atau kajian bahasa dan perspekstif fungsional. Artinya, kajian ini mencoba menjelaskan aspekaspek struktur bahasa dengan mengacu pada pengaruh-pengaruh dan sebab-sebab nonbahasa.

Pragmatik sebenarnya merupakan bagian dari ilmu tanda atau semiotik atau semiotika. Pemakaian istilah pragmatik (pragmatics) dipopulerkan oleh seorang filosof bernama Charles Morris (1938), yang mempunyai perhatian besar pada ilmu pengetahuan tentang tanda-tanda, atau semiotik (semiotics). Dalam 
semiotik, Morris membedakan tiga cabang yang berbeda dalam penyelidikan, yaitu: sintaktik (syntactic) atau sintaksis (syntax) yaitu telaah tentang relasi formal dari tanda yang satu dengan tanda yang lain (mempelajari hubungan satuan lingual dengan satuan lingual lain: lain dengan tanda); semantik (semantics) yaitu telaah tentang hubungan tanda-tanda dengan objek dimana tanda-tanda itu diterapkan (ditandainya) (atau hubungan antara penanda dan petanda (significant danu signifie/ yang ditandai)); dan pragmatik yaitu telaah tentang hubungan tanda-tanda dengan penafsir (interpreters). Ketiga cabang tersebut kemudian lebih dikenal dengan teori trikotomi.

Salah satu bagian dalam kajian pragmatik adalah analisis tindak tutur. Sebagaimana diketahui bersama, bahasa adalah alat komunikasi yang dipergunakan oleh semua orang dalam kehidupan seharihari. Tanpa menggunakan bahasa seseorang tidak akan dapat bersosialisasi, bahkan mungkin juga tidak akan dapat memenuhi kebutuhan hidupnya. Seseorang pada umumnya tidak pandai memilih petuturan yang baik atau bahkan tidak memahami makna dan jenis petuturan yang seharusnya mereka pergunakan, baik di lingkungan instansi maupun di lingkungan masyarakat pada umumnya. Hal ini dapat terjadi karena beberapa faktor, diantaranya faktor pengetahuan seseorang, faktor lingkungan, faktor pergaulan, faktor keadaan daerah, dan faktor intern seseorang. Sebagai salah satu contoh petuturan yang disampaikan seseorang yang kesehariannya di terminal sangatlah jauh berbeda dengan petuturan yang disampaikan oleh seorang dosen yang kesehariannya menyampaikan kajian-kajian ilmiah kepada mahasiswa di lingkungan kampus.

Meski petuturan ini suatu yang penting dalam keberhasilan komunikasi dan proses sosial seseorang, namun tidak sedikit yang masih melakukan kesalahan bertutur. Padahal sebetulnya dimana saja kita berada atau kepada siapa kita menyampaikan tuturan, tentu harus sesuai dengan etika dan jenis petuturan yang benar.

Presiden Jokowi yang baru dilantik pada 20 Oktober 2014 harus turut serta dalam pertemuan internasional APEC yang ke-26.

Pada pertemuan itu Presiden Jokowi menyampaikan pidato sebagaimana juga presiden negaranegara lainnya. Pertemuan yang diselenggarakan di Beijing pada 
tanggal 10-12 November 2014 dihadiri antara lain oleh Presiden Tiongkok Xi Jinping, Presiden A.S Barack Obama, Presiden Korea Selatan Park Geun-hye, Presiden Rusia Vladimir Putin dan Perdana Menteri Jepang Shinzo Abe. Pada ajang internasional ini sudah barang tentu bahasa yang digunakan adalah Bahasa Inggris. Selain bahasa yang digunakan, satu hal lagi yang penting adalah isi, gagasan serta pikiran yang disampaikan oleh para kepala negara kepada peserta APEC 2014 lainnya yang notabene adalah para pemimpin negara-negara di Asia Pasifik. Hal ini merupakan salah satu alasan ketertarikan penulis dalam melakukan penelitian ini dengan memfokuskan pada dua hal yang mesti dijawab yaitu jenis tindak tutur apa saja yang terdapat dalam pidato Presiden Jokowi pada pertemuan APEC 2014 serta apa saja bentuk dan fungsi dari ujaran presiden dalam pidato tersebut.

Penelitian ini menggunakan metode deskriptif kualitatif seperti yang dikemukakan oleh Djadjasudarma (1993:10) yang menyatakan bahwa penelitian kualitatif merupakan prosedur penelitian yang menghasilkan data deskriptif berupa data lisan ataupun data tertulis. Selanjutnya, metode ini berupaya memberikan deskripsi yang bersifat sistematis, faktual dan akurat mengenai data, sifat-sifat serta hubungan fenomena-fenomena yang diteliti sehingga akan didapatkan gambaran data secara ilmiah (Djadjasudarma, 1993:8). Sumber data utama penelitian ini adalah pidato Presiden Jokowi pada pertemuan APEC 2014 di Cina yang penulis unggah dari Youtube. Adapun instrumen dalam penelitian ini adalah transkip ujaran pidato Presiden Jokowi. Peneliti melakukan pengamatan langsung terhadap berbagai gejala yang tampak pada data.

Analisis data akan dilakukan dengan mengikuti alur metode padan dan metode agih; metode padan dengan teknik pilah unsur dan metode agih dengan teknik bagi unsur langsung (Sudaryanto, 1993). Seluruh data akan dipilah dan setelah pemilahan dilakukan, peneliti menerapkan metode agih untuk melihat unsur lingual. Kemudian, data yang telah terkumpul dan terkelompok akan diuraikan dengan menggunakan alur metode kualitatif dengan pengertian bahwa setiap langkah analisis dilakukan sesuai dengan penelusuran kaidah bentuk, klasifikasi dan fungsi ujaran dalam kajian pragmatik. 
Metode penyajian hasil analisis data dalam penelitian ini menggunakan metode informal dan formal (Sudaryanto, 1993:145). Adapun metode penyajian informal berupa perumusan dengan penggunaan kata-kata, sedangkan metode penyajian formal berupa perumusan dengan tanda, dan lambang, seperti tanda tambah, kurung, titik dua, titik koma, tanda tanya, tanda panah, kurung biasa, kurung kurawa, huruf sebagai singkatan nama, dan sebagainya.

\section{KONSEP}

Berdasarkan pengamatan penulis, belum ada peneliti lain yang secara spesifik mengkaji pidato. Umumnya, kajian tindak tutur diterapkan pada naskah percakapan ataupun novel. Penelitian yang serupa dengan penelitian penulis adalah penelitian Ending (2014) yang mengkaji tindak tutur pada novel popular karya Danielle Steel yang berjudul Leap of Faith.

Ending (2014) meneliti bagaimana bentuk dan fungsi ujaran dalam percakapan tokohtokoh utama dalam novel Leap of Faith karya Danielle Steel. Hal ini berarti penutur mempunyai lawan berbicara. Ending berkesimpulan bahwa bentuk dan fungsi tindak tutur dalam novel tersebut di atas cenderung dipengaruhi alur cerita. Sedangkan dalam penelitian ini, kajian akan lebih kompleks karena data yang dianalisis adalah ujuran yang bernuansa power karena dituturkan oleh seorang presiden tanpa ada lawan bicara.

Penelitian ini memakai konsep bahasa dan pragmatik. Berikut penjelasannya:

\section{Bahasa dan Pragmatik}

Bahasa, dipahami sebagai kumpulan norma-norma perkataan dari komunitas tertentu, juga termasuk bagian dari kultur yang lebih besar dari masyarakat penuturnya. Bahasa tidak hanya berbeda dari segi pengucapan, kosakata, atau tatabahasa, tapi juga berbeda dalam "kultur berbicara". Manusia menggunakan bahasa sebagai cara memberikan signal identitas antara grup kultur dan perbedaan dengan yang lainnya. Perbedaan linguistik bisa menjadi penanda penting dari pemisahan antara kelompok-kelompok sosial, contohnya menuturkan sebuah bahasa dengan aksen khusus bisa menyatakan keanggotaan dari sebuah etnis tertentu atau kelas sosial, wilayah asal, atau status sebagai penutur bahasa kedua. Bentuk-bentuk perbedaan ini bukan bagian 
dari sistem linguistik, tapi adalah suatu bagian penting bagaimana pengguna bahasa menggunakan bahasa sebagai alat sosial untuk membangun kelompoknya.

Chaer (2003: 30) menyebutkan bahwa bahasa adalah alat verbal untuk komunikasi. Sebelumnya (1994), Chaer menegaskan bahwa bahasa sebagai "suatu lambang bunyi yang bersifat arbitrer yang digunakan oleh sekelompok anggota masyarakat untuk berinteraksi dan mengidentifikasi diri, bahasa bukan saja "property" yang ada dalam diri manusia yang dikaji sepihak oleh para ahli bahasa, tetapi bahasa juga alat komunikasi antar personal. Komunikasi selalu diiringi oleh interpretasi yang didalamnya terkandung makna. Dari sudut pandang wacana, makna tidak pernah bersifat absolut; tetapi selalu ditentukan oleh berbagai konteks yang mengacu kepada tanda-tanda yang terdapat dalam kehidupan manusia yang didalamnya ada budaya. Dengan kata lain, bahasa tidak pernah lepas dari konteks budaya karena kebudayaan atau kultur secara menyeluruh terbentuk di dalamnya sejarah dan diteruskan dari masa ke masa melalui tradisi yang mencakup organisasi, sosial, ekonomi, agama, kepercayaan, kebiasaan, hukum, seni, teknik, dan ilmu. Dengan demikian, jelas bahwa budaya terbentuk melalui proses perjalanan waktu dalam sejarah yang berkembang dari generasi ke generasi berikutnya.

Linguistik sebagai cabang ilmu kajian bahasa memiliki berbagai cabang. Cabang-cabang itu diantaranya adalah fonologi, morfologi, sintaksis, semantik, pragmatik, dan sebagainya. Jadi, linguistik memiliki berbagai cabang. Di antara cabang tersebut memiliki hubungan yang menelaah tentang makna-makna satuan lingual yaitu semantik dan pragmatik. Hal itu didukung oleh Wijana (2006: 2) berpendapat semantik mempelajari makna secara internal, sedangkan pragmatik mempelajari makna secara eksternal. Bertolak dari pendapat Leech (dalam Wijana, 1996: 4), yaitu kehadiran pragmatik hanyalah tahap terakhir dari perkembangan linguistik yang berangsur-angsur, mulai dari disiplin ilmu yang mengenai data fisik tuturan menjadi disiplin ilmu yang sangat luas bersangkutan dengan bentuk, makna, dan konteks.

Dalam hal ini, beberapa pakar mendefenisikan pragmatik. Pragmatik merupakan menelaah ucapan-ucapan khusus dalam situasi - situasi khusus dan 
memusatkan perhatian pada aneka ragam cara yang merupakan wadah aneka konteks sosial. Wijana (1996: 1), berpendapat pragmatik adalah cabang ilmu bahasa yang mempelajari struktur bahasa secara eksternal, yakni bagaimana satuan kebahasaan itu digunakan di dalam komunikasi. Berbeda dengan Wijana, Yule (2006: 5), mengungkapkan bahwa pragmatik adalah studi tentang hubungan antara bentuk-bentuk linguistik dan pemakai bentuk-bentuk itu.

Dari kedua pendapat di atas, Levinson (dalam Tarigan, 2009:

31), mengungkapkan defenisi pragmatik lebih detal, yaitu telaah mengenai relasi antara bahasa dan konteks yang merupakan dasar bagi suatu catatan atau laporan pemahaman bahasa, dengan kata lain telaah mengenai kemampuan pemakai bahasa menghubungkan serta penyerasian kalimat-kalimat dan konteks secara tepat.

Pandangan-pandangan tersebut seyogyanya memiliki arti yang sama, bahwa pragmatik adalah bidang linguistik yang mengkaji telaah tuturan bahasa dari segi makna. Sejalan dengan pendapat di atas, pragmatik mengkaji tentang tuturan bahasa. Dengan demikian pragmatik sangat erat dengan tindak tutur. Tuturan tersebut memilki makna, maksud atau tujuan, sehingga perlu dikaji dengan bidang pragmatik.

\section{HASIL DAN PEMBAHASAN}

Hasil : Klasifikasi Bentuk dan Fungsi Tindak Tutur Pidato Presiden Jokowi

\section{Representatif}

Ujaran pidato Presiden Jokowi pada pertemuan APEC 2014 di Cina dipaparkan dan diklasifikasikan pada table di bawah ini:

Tabel 1 Klasifikasi dan Fungsi Ujaran Pidato Presiden

\begin{tabular}{|l|l|l|l|}
\hline No & Ujaran & Bentuk & Fungsi \\
\hline 1 & $\begin{array}{l}\text { "First on behalf Representatif Menyapa of the } \\
\text { Indonesian } \\
\text { government and } \\
\text { the people of In- } \\
\text { donesia, I Would } \\
\text { like to thank you } \\
\text { for coming to my } \\
\text { presentation" }\end{array}$ & & \\
\hline 2 & $\begin{array}{l}\text { "Because you know } \\
\text { I was a business- } \\
\text { man years ago" }\end{array}$ & Representatif & Menyatakan \\
\hline 3 & $\begin{array}{l}\text { "We have a popula- } \\
\text { tion of 240 millions } \\
\text { and the distance is } \\
\text { like from London } \\
\text { in UK to Istanbul } \\
\text { in Turkey" }\end{array}$ & Representatif & Mengatakan \\
\hline 4 & $\begin{array}{l}\text { "Our national bud- } \\
\text { get for 2015 is \$167 } \\
\text { billion and for fuel } \\
\text { subsidy is \$27 bil- } \\
\text { lion" }\end{array}$ & Representatif & Mengatakan \\
\hline 5 & "It's huge" & \\
\hline
\end{tabular}




\begin{tabular}{|c|c|c|c|}
\hline 6 & $\begin{array}{l}\text { "From consumptive } \\
\text { activities to produc- } \\
\text { tive activities" }\end{array}$ & Representatif & $\begin{array}{l}\text { M e n e g a s - } \\
\text { kan }\end{array}$ \\
\hline 7 & $\begin{array}{l}\text { "As you know, we } \\
\text { have } 17.000 \text { island, } \\
\text { so we need seaports } \\
\text { and we need deep } \\
\text { seaports" }\end{array}$ & Representatif & Menyatakan \\
\hline 8 & $\begin{array}{l}\text { "This is the poten- } \\
\text { tial ports in Indo- } \\
\text { nesia" }\end{array}$ & Representatif & Menyatakan \\
\hline 9 & $\begin{array}{l}\text { "Now we have al- } \\
\text { ready in Java" }\end{array}$ & Representatif & $\begin{array}{l}\text { M e n e g a s - } \\
\text { kan }\end{array}$ \\
\hline 10 & $\begin{array}{l}\text { "Now we talk about } \\
\text { mass transportation" }\end{array}$ & Representatif & $\begin{array}{l}\text { M e n e g a s - } \\
\text { kan }\end{array}$ \\
\hline 11 & $\begin{array}{l}\text { "We have started in } \\
\text { Jakarta last year" }\end{array}$ & Representatif & $\begin{array}{l}\text { M e n e g a s - } \\
\text { kan }\end{array}$ \\
\hline 12 & $\begin{array}{l}\text { "Because you know } \\
\text { our tnational bud- } \\
\text { get is limited" }\end{array}$ & Representatif & Menyatakan \\
\hline 13 & $\begin{array}{l}\text { "Now we talk about } \\
\text { our maritime agen- } \\
\text { da" }\end{array}$ & Representatif & $\begin{array}{l}\text { M e n e g a s - } \\
\text { kan }\end{array}$ \\
\hline 14 & $\begin{array}{l}\text { "Sea toll is mari- } \\
\text { time transportation } \\
\text { system to make our } \\
\text { transportation cost } \\
\text { lower, to make our } \\
\text { transportation cost } \\
\text { more efficient" }\end{array}$ & Representatif & $\begin{array}{l}\text { Memapar- } \\
\text { kan }\end{array}$ \\
\hline 15 & $\begin{array}{l}\text { "For example, the } \\
\text { price of the cement, } \\
\text { one sack cement, } \\
\text { but in Papua island } \\
\text { the pricw ia } \$ 150 \\
\text { per sack cement" }\end{array}$ & Representatif & $\begin{array}{l}\text { Memapar- } \\
\text { kan }\end{array}$ \\
\hline 16 & $\begin{array}{l}\text { "Electricity. We } \\
\text { need power plants. } \\
\text { We need around } \\
35.000 \text { megavolts } \\
\text { to build on our in- } \\
\text { dustries, to build } \\
\text { our projects, to build } \\
\text { our industrial zones, } \\
\text { our manufacturing } \\
\text { zones. So, we need } \\
\text { power plants" }\end{array}$ & Representatif & $\begin{array}{l}\text { Memapar- } \\
\text { kan }\end{array}$ \\
\hline 17 & $\begin{array}{l}\text { "Because we need } \\
\text { our power plants } \\
\text { for manufactur- } \\
\text { ing, for industrial } \\
\text { zones" }\end{array}$ & Representatif & Mengatakan \\
\hline
\end{tabular}

\begin{tabular}{|c|c|c|c|}
\hline 18 & $\begin{array}{l}\text { "Many investors, } \\
\text { a lot of investors, } \\
\text { when they come to } \\
\text { me, most of them } \\
\text { always complain } \\
\text { abour land acqui- } \\
\text { sition" }\end{array}$ & Representatif & Mengatakan \\
\hline 19 & $\begin{array}{l}\text { "I have experience } \\
\text { wth land acquisi- } \\
\text { tion when I was a } \\
\text { governor. We have } \\
\text { a project, the Ja- } \\
\text { karta outer Ring } \\
\text { Road, started } 15 \\
\text { years ago but was } \\
\text { atopped } 8 \text { years } \\
\text { ago, because we } \\
\text { have a problem } \\
\text { her : } 1.5 \text { kilome- } \\
\text { ters unfinished } \\
\text { because there is } \\
143 \text { families who } \\
\text { do not accept with } \\
\text { the compensation } \\
\text { price. So, last year } \\
\text { I invite them. I go } \\
\text { to them the I invite } \\
\text { them to lunch and } \\
\text { dinner. Four times. } \\
\text { Ah, this is me. I } \\
\text { invite them and } \\
\text { then we talk about } \\
\text { the problem. Four } \\
\text { time. Four times } \\
\text { meeting. And the } \\
\text { problem is clear" }\end{array}$ & $\begin{array}{l}\text { Represen- } \\
\text { tatif }\end{array}$ & $\begin{array}{l}\text { Memapar- } \\
\text { kan }\end{array}$ \\
\hline 20 & $\begin{array}{l}\text { "And now the toll } \\
\text { roads has been } \\
\text { used (starting) } 7 \\
\text { months ago"” }\end{array}$ & $\begin{array}{l}\text { Represen- } \\
\text { tatif }\end{array}$ & $\begin{array}{l}\text { Menegas- } \\
\text { kan }\end{array}$ \\
\hline 21 & $\begin{array}{l}\text { "Now we talk busi- } \\
\text { ness permit" }\end{array}$ & $\begin{array}{l}\text { Represen- } \\
\text { tatif }\end{array}$ & $\begin{array}{l}\text { Menegas- } \\
\text { kan }\end{array}$ \\
\hline 22 & $\begin{array}{l}\text { "Finally, again on } \\
\text { behalf of the Indo- } \\
\text { nesian government } \\
\text { and the people of } \\
\text { Indonesia, I would } \\
\text { like to thank you for } \\
\text { your listening my } \\
\text { presentation" }\end{array}$ & $\begin{array}{l}\text { Represen- } \\
\text { tatif }\end{array}$ & $\begin{array}{l}\text { M e n y i m- } \\
\text { pulkan }\end{array}$ \\
\hline
\end{tabular}




\section{Direktif}

\section{Ujaran pidato Presiden dalam} bentuk direktif dideskripsikan pada table di bawah ini

Tabel 2 klasifikasi dan fungsi direktif

\begin{tabular}{|l|l|l|l|}
\hline No & Ujaran & Bentuk & Fungsi \\
\hline 1 & $\begin{array}{l}\text { "The picture shows } \\
\text { yiu our map of In- } \\
\text { donesia" }\end{array}$ & Direktif & $\begin{array}{l}\text { Meng } \\
\text { i n f o r m a s i- } \\
\text { kan }\end{array}$ \\
\hline 2 & $\begin{array}{l}\text { "And imagine, we } \\
\text { have 17.000 islands } \\
17.000 \text { islands" }\end{array}$ & Direktif & $\begin{array}{l}\text { Memerintah- } \\
\text { kan }\end{array}$ \\
\hline 3 & "What is sea toll" & Direktif & Menanyakan \\
\hline 4 & $\begin{array}{l}\text { "Im a g i ne, 2 5 } \\
\text { times" }\end{array}$ & Direktif & Memerintah \\
\hline 5 & $\begin{array}{l}\text { "We are waiting } \\
\text { for you to come to } \\
\text { Indonesia" }\end{array}$ & Direktif & Memohon \\
\hline 6 & $\begin{array}{l}\text { "We are wainting } \\
\text { for you to invest in } \\
\text { Indonesia" }\end{array}$ & Direktif & Memohon \\
\hline
\end{tabular}

\section{Komisif}

Ujaran- ujaran dalam bentuk komisif pada pidato Presiden Jokowi dipaparkan pada table berikut :

Table 3 bentuk dan fungsi komisif

\begin{tabular}{|r|l|l|l|}
\hline No & Ujaran & Bentuk & Fungsi \\
\hline 1 & $\begin{array}{l}\text { "So we want to } \\
\text { channel fuel subsidy } \\
\text { from consumption to } \\
\text { the productive ac- } \\
\text { tivities" }\end{array}$ & Komisif & Berjanji \\
\hline 2 & $\begin{array}{l}\text { "We want to channel } \\
\text { our fuel subsidy to } \\
\text { farm for seeds, for } \\
\text { fertilizers, and also } \\
\text { for irrigation" }\end{array}$ & Komisif & Berjanji \\
\hline 3 & $\begin{array}{l}\text { "And we want to } \\
\text { build dams-25 dams } \\
\text { in 5 years from our } \\
\text { fuel subsidy to main- } \\
\text { tainthe water supply } \\
\text { to the farming area" }\end{array}$ & Komisif & Berjanji \\
\hline
\end{tabular}

\begin{tabular}{|c|c|c|c|}
\hline 4 & $\begin{array}{l}\text { "Some subsidy we } \\
\text { want ton channel to } \\
\text { the fishermen, to give } \\
\text { them boat engines, } \\
\text { to give them refrig- } \\
\text { erators" }\end{array}$ & Komisif & Berjanji \\
\hline 5 & $\begin{array}{l}\text { "We want to in- } \\
\text { crease the income of } \\
\text { the fishermen" }\end{array}$ & Komisif & Berjanji \\
\hline 6 & $\begin{array}{l}\text { "Some fuel subsidy } \\
\text { we want to give to mi- } \\
\text { cro and small enter- } \\
\text { prises in the villages" }\end{array}$ & Komisif & Berjanji \\
\hline 7 & $\begin{array}{l}\text { "We want to help } \\
\text { them raise their } \\
\text { working capital" }\end{array}$ & Komisif & Berjanji \\
\hline 8 & $\begin{array}{l}\text { "And some subsidy } \\
\text { we want to channel } \\
\text { to the health pro- } \\
\text { gram, the education } \\
\text { program" }\end{array}$ & Komisif & Berjanji \\
\hline 9 & $\begin{array}{l}\text { "And some subsidy } \\
\text { we want to channel } \\
\text { to infrastructure" }\end{array}$ & Komisif & Berjanji \\
\hline 10 & $\begin{array}{l}\text { "In } 5 \text { years we want } \\
\text { to build } 24 \text { seaports } \\
\text { and deep seaports" }\end{array}$ & Komisif & Berjanji \\
\hline 11 & $\begin{array}{l}\text { "And this is your op- } \\
\text { portunity: } 24 \text { seaports } \\
\text { and deep seaports" }\end{array}$ & Komisif & $\begin{array}{l}\text { Menawar } \\
\text { kan }\end{array}$ \\
\hline 12 & $\begin{array}{l}\text { "In 2009, the capac- } \\
\text { ity is } 3.6 \text { millions } \\
\text { TEUs a yearm and } \\
\text { our plan in } 2017 \text { is } \\
\text { around } 15 \text { million } \\
\text { TEUs a year" } \\
\end{array}$ & Komisif & Berjanji \\
\hline 13 & $\begin{array}{l}\text { "This is your op- } \\
\text { portunity" }\end{array}$ & Komisif & \begin{tabular}{|l|} 
Menawar- \\
kan \\
\end{tabular} \\
\hline 14 & $\begin{array}{l}\text { "We want to build in } \\
\text { Sumatera island, in } \\
\text { Kalimantan island, } \\
\text { in Java island, in } \\
\text { Sulawesi island, in } \\
\text { Maluku island, also } \\
\text { Papua island" }\end{array}$ & Komisif & Berjanji \\
\hline 15 & $\begin{array}{l}\text { "And we want to } \\
\text { buils our railway } \\
\text { track, railway net- } \\
\text { work" }\end{array}$ & Komisif & Berjanji \\
\hline
\end{tabular}




\begin{tabular}{|c|c|c|c|}
\hline 16 & $\begin{array}{l}\text { "And we want to } \\
\text { build in Sumatera is- } \\
\text { land, in Kalimantan } \\
\text { island, in Sulawesi } \\
\text { island and also in } \\
\text { Papua island" }\end{array}$ & Komisif & Berjanji \\
\hline 17 & $\begin{array}{l}\text { "This is your op- } \\
\text { portunity" }\end{array}$ & Komisif & $\begin{array}{l}\text { Menawar- } \\
\text { kan }\end{array}$ \\
\hline 18 & $\begin{array}{l}\text { "We want to build } \\
\text { our mass transpor- } \\
\text { tationin } 6 \text { big cities } \\
\text { in Indonesia" }\end{array}$ & Komisif & Berjanji \\
\hline 19 & $\begin{array}{l}\text { "And we want to } \\
\text { build in Medan, In } \\
\text { Makassar, in Sema- } \\
\text { rang, In Bandung, } \\
\text { in Surabaya" } \\
\end{array}$ & Komisif & Berjanji \\
\hline 20 & $\begin{array}{l}\text { "So, this is also yous } \\
\text { opportunity" }\end{array}$ & Komisif & $\begin{array}{l}\text { Menawar- } \\
\text { kan }\end{array}$ \\
\hline 21 & $\begin{array}{l}\text { "We want to build } \\
\text { sea toll" }\end{array}$ & Komisif & Berjanji \\
\hline 22 & $\begin{array}{l}\text { "We want to build } \\
\text { from the west to the } \\
\text { east" }\end{array}$ & Komisif & Berjanji \\
\hline 23 & $\begin{array}{l}\text { "We hope not only } \\
\text { the vessels can enter } \\
\text { our sea toll but also } \\
\text { mother vessels can } \\
\text { enter the sea toll" }\end{array}$ & Komisif & $\begin{array}{l}\text { B e r - } \\
\text { harap }\end{array}$ \\
\hline 24 & $\begin{array}{l}\text { "So we hope with our } \\
\text { sea toll the price in our } \\
\text { islands is the same" }\end{array}$ & Komisif & $\begin{array}{l}\text { B e r - } \\
\text { harap }\end{array}$ \\
\hline 25 & $\begin{array}{l}\text { "This is also your } \\
\text { opportunity to invest } \\
\text { in this project" }\end{array}$ & Komisif & $\begin{array}{l}\text { B e r - } \\
\text { harap }\end{array}$ \\
\hline 26 & $\begin{array}{l}\text { "I will push my min- } \\
\text { isters, my governors, } \\
\text { my mayors to help } \\
\text { clear this problem" }\end{array}$ & Komisif & Berjanji \\
\hline 27 & $\begin{array}{l}\text { "We have national } \\
\text { one-stop service of- } \\
\text { fice that can help you, } \\
\text { that will serve you, } \\
\text { that will facilitate you, } \\
\text { that will give you your } \\
\text { business permit. For } \\
\text { example, principle } \\
\text { business permit needs } \\
3 \text { days to process }\end{array}$ & Komisif & Berjanji \\
\hline
\end{tabular}

\section{Ekspresif}

Bentuk ekspresif dari ujaran pidato Presiden Jokowi di deskripsikan pada table dibawah ini:

Tabel 4 Bentuk dan Fungsi Ekspresif

\begin{tabular}{|l|l|l|l|}
\hline No & Ujaran & Bentuk & Fungsi \\
\hline 1 & $\begin{array}{l}\text { "I would like to } \\
\text { thank you for } \\
\text { coming to my } \\
\text { presentation" }\end{array}$ & Ekspresif & Berterimakasih \\
\hline 2 & $\begin{array}{l}\text { "Today, I am } \\
\text { happy, Iam very } \\
\text { happy to be with } \\
\text { you" }\end{array}$ & Ekspresif & Menyenangkan \\
\hline 3 & $\begin{array}{l}\text { "So, this morn- } \\
\text { ing, I am very } \\
\text { happy because } \\
\text { we c a n t a l } \\
\text { about business, } \\
\text { about investment } \\
\text { with all ofyou" }\end{array}$ & Ekspresif & Menyenangkan \\
\hline 4 & $\begin{array}{l}\text { "I would like to } \\
\text { thank you for } \\
\text { your lietening } \\
\text { my presenta- } \\
\text { tion" }\end{array}$ & Ekspresif & Berterimakasih \\
\hline 5 & $\begin{array}{l}\text { "Tha n } k \text { y o u, Ekspresif } \\
\text { thank you" }\end{array}$ & Berterimakasih \\
\hline
\end{tabular}

\section{PEMBAHASAN}

Contoh data pada nomor (1) pada tabel di atas adalah jenis representatif . Data tersebut menyatakan bahwa Jokowi bertindak merepresentasikan diri sebagai perwakilan resmi Indonesia. Sementara fungsi ujaran tersebut berupa greeting (sapaan). Contoh ujaran-ujaran pada tabel 2 adalah bentuk direktif atau suatu arahan/ perintah ajakan yang meminta, menginformasikan dan memerintahkan. Jokowi berupaya agar pendengar melakukan sesuatu. 
Contoh pada ujaran -ujaran pada tabel 3 adalah bentuk komisif yang mencoba meyakinkan lawan bicara tentang janji yang akan diwujudkan.

Dari semua data di atas, ditemukan bahwa fungsi-fungsinya cenderung promising atau berjanji. Hal ini dikarenakan kondisi negara yang sedang dalam pembangunan dalam sektor industri. Dengan kata lain, presiden mengundang penanam modal untuk berinvestasi di Indonesia.

Adapun contoh ujaran-ujaran pidato Presiden Jokowi pada tabel 4 adalah bentuk ekspresif. Ekpresi presiden terlihat senang ketika membuka pidatonya dan tentunya secara psikologis presiden berharap semua hadirin juga berbahagia. Hal ini tampak pada fungsi ujaran yang berterimakasih (Thanking).

\section{SIMPULAN DAN SARAN}

Dari hasil analisis data, ditemukan 22 bentuk representatif, 6 direktif, 27 komisif, 5 ekspresif dan tidak ada bentuk deklaratif. Bentuk ujaran komisif merupakan bentuk yang dominan pada pidato Presiden Jokowi. Hal ini sesuai dengan konteks dimana Jokowi membuka hubungan kerjasama dalam sektor penanaman modal. Dari sisi fungsi, promising atau menjanjikan juga paling dominan. Presiden Jokowi menjanjikan investor dalam konteks yang kondusif.

\section{Saran}

Berdasarkan simpulan di atas, saran penulis sebagai berikut:

1. Diharapkan penelitian ini dapat ditindak lanjuti dari aspek lain oleh peneliti lain.

2. Diharapkan penelitian ini dapat menambah pengetahuan tentang pemahaman makna ujaran dalam hal pragmatik.

\section{DAFTAR PUSTAKA}

Allen, K. 1996. Linguistic Meaning Vol.1\&2. London: Routledge \& Kegan Paul.

Austin, J.L. 1962. How To Do Thing With Wor. London: Oxford University Press.

Austin, J.L. 1962. Performative Contantive, An Essay in Philosophy of Language. C a $\mathrm{mb}$ rid g e : C a m b ri d g e university press.

Birner, Betty J. 2013. Introduction to Pragmatics. Singapore : Wiley-Blackwell

Chaer,A. 1994. Linguistik Umum. Jakarta: Rhineka

Cutting, Joan. 2002. Pragmatic and 
Discourse. London: Routledge

Flick, Uwe; Kardorff, Erns Von ; Steinke, Ines. 2000. A Companion to Qualitative Research. London: Sage

Griffiths, Patrick. 2006. An Introduction to English Semantics and Pragmatics. England: Edinburgh University Press.

Horn, Laurence R; Ward, Gregory. 2006 . The Handbook of pragmatics. United Kingdom: Blackwell

Leech, G. 1983. Principle of Pragmatics. London Longman Ltd.

Levinson.S.C. 1983. Pragmatics. Britain: Cambridge University Press
Miles, Matthew B \& A. Michael Huberman. 1994. Qualitative data Analysis: An Expanded Sourcebook. London: Sage Publications

Moleong, J.L.2000. Metodologi Penelitian Kualitatif. Bandung: Pt. Remaja Rosdakarya.

Searle, J.R. 1969. What is Speech Act: An Essay in Philosophy of Language. Cambridge: Cambridge University Press.

Sudaryanto. 1993. Metode dan Aneka Teknik Analisis Bahasa. Jakarta: Dua Wacana University. 